\title{
Utility Based Portfolio Optimization through Integer Programming Under Stochastic Markets
}

\author{
Afreen Arif H., T.P.M. Pakkala
}

\begin{abstract}
Optimization of a portfolio based on utility functions has been a long line of research in the past. In practice, the solutions discussed earlier are approximated to integers, because of the availability of stocks in integer units. But utility functions are quite sensitive to the amounts invested. Thus mere approximations may lead to loss in utility. In this paper, a procedure called the Integer solution to Expected Utility Maximization (ISEUM) is suggested, where the investor can obtain a pure integer solution to the portfolio optimization problem. This is discussed under the assumption of stochastic markets, where the market states follow a Markov chain. Illustrations showing three different types of investors are presented and the corresponding optimal integer solution is obtained for each market state. In each case, solutions based on the ISEUM procedure are compared with non-integer and corresponding approximated solutions. The loss due to approximation is assessed for each case.
\end{abstract}

Keywords: Integer programming, Markov chain, Portfolio optimization, , Utility function.

\section{INTRODUCTION}

In the past, a lot of research work has been done in the field of mean variance optimization for portfolio selection. The work by [1], [2] and [3] in this area has been highly appreciated. Many have used and given improvements to the methods suggested by them. Most commonly used methods for obtaining the solutions of the model suggested by them, are quadratic and dynamic programming techniques

Mean variance optimum portfolio does not take into the risk preferences of the various types of investors present in the market. Different types of investors can be represented through different utility functions and the optimum portfolio can be obtained based on the utility. Such solutions have been attempted by many. [4] worked utility functions obtaining myopic policies; [3] studied special utility functions with logarithmic and power structures. Lately, [5] has shown the use of utility functions for finding the optimal portfolio for a particular investor.

Manuscript published on November 30, 2019.

* Correspondence Author

Afreen Arif $\mathbf{H}^{*}$., Department of Mathematics and Statistics, Zayed University, Dubai, UAE. Email: afreenathiqa@hotmail.com

T.P.M. Pakkala, Justice K.S. Hegde Institute of Management, NMAMIT, Nitte, India. Email: tpm_pakkala@yahoo.com

(c) The Authors. Published by Blue Eyes Intelligence Engineering and Sciences Publication (BEIESP). This is an open access article under the CC-BY-NC-ND license http://creativecommons.org/licenses/by-nc-nd/4.0/
[6] reviews 208 articles where the different models and approaches used to analyze the problem of optimum portfolio, for single period and multi-period case. [7] highlights that a lot of work is done in this direction. In a multi-period setting, the assumption of uncorrelated asset returns is not realistic as seen by [8] and [9]. This dependence or correlation can be modelled through a stochastic market process, like a Markov chain. This affects all deterministic and probabilistic parameters of the model. Solution of these models is given through dynamic programming techniques.

[10] highlights the opinions of [11], who observed that the standard portfolio models by [1] and [2] are inappropriate for the small individual investor. The portfolios generated usually include a larger number of assets than the small investor has resources to manage. As the commission rates are high, he must pay on his odd lot purchases and sales. A small investor cannot afford to be as diversified as the mutual funds, which by law are required to hold at least twenty securities but in most cases hold more than one hundred. Because of these problems an individual investor may not be able to optimally approximate the non- integer solution to his problem to an integer solution. Moreover, an individual investor may have to construct a portfolio of his own, which will require him to purchase stock in integer units only.

[10] therefore suggests the use of integer programming techniques in portfolio optimization. He suggests a mean-variance portfolio selection model suitable for the small investor which is formulated as a sequence of quadratic integer programming problems. [12] also have done similar work in this area which makes use of the analogy of dynamic programming technique.

[13] highlight that Markowitz model has been increasingly criticised as it disregards individual investors' preferences. [14] observed that in many cases investors are not actually buying efficient portfolios, but are buying those securities which are behind the efficient frontier. A compromise programming model for an 'average' investor was proposed by [15], which was later modified to approximate the optimum portfolio of an individual investor [16]. [17] described the use of objective and subjective measures for assets. Their idea leads to a simple linear programming model. [18] argued that most models do not show the multidimensional nature of the problem and outline a need for such a view in portfolio management. For further references on the use of optimization models for portfolio selection the reader is referred to [19]. Working in this direction [13] suggest a mixed integer programming model with multiple objective functions. 
The work in this area has been restricted to only mean variance portfolio models. Since our concern here is the small individual investor, who definitely has some distinct behaviour towards risk, which can be represented using an appropriate utility function. Hence there is a need for obtaining an integer solution for such an investor based on his/her utility function.

In the literature it is seen that so far no "Pure" integer programming method or algorithm is suggested for an individual investor who wants to maximize his expected utility. In this paper a procedure is suggested by which a small investor can obtain a pure-integer optimum portfolio solution based on his/her known utility function. The market states are modelled as a Markov chain. The algorithm suggested here gives a market state based solution to the problem. The suggested solution is wealth dependent. The integer solution is compared with the exact non-integer solution, for each market state. This is done for various commonly used utility functions and different wealth levels of investors.

\section{MODEL AND MARKET ASSUMPTIONS.}

The asset returns of a portfolio vary continuously in a random manner. Normal and lognormal distributions have been used to model them. The variations in the returns may be due to internal and/or external forces which could be at a local and/or at a global level. Investment decision vary because of these forces as well as the correlation among asset returns. [9] highlight that modelling a stochastic financial market by a Markov chain is a reasonable approach in this situation. They argue that off late a lot of literature discuss stochastic market process, for modelling various parameters of a financial model, to make the model more realistic. They also highlight that discrete state space continuous-time Markov chains are used in a lot recently ([21],[22],[23],[24]).

\section{A. Wealth Dynamics Equation}

Suppose that the state of the market in period $n$ is denoted by $Y_{n}$ and $Y=\left\{Y_{n} ; n=0,1,2, \ldots\right\}$ is a Markov chain with a discrete state space, $\mathrm{E}$ and transition matrix, Q. The changes in the prices of the market portfolio can be captured using a Markov Chain. Let R(i) denote the random vector of asset returns in any period given that the stochastic market is in state $i$. The means, variances and covariance of asset returns depend only on the current state of the stochastic market. The market consists of one riskless asset with known return $r_{f}(i)$ and standard deviation $\sigma_{f}(i)=0$; and $m$ risky assets with random returns $R^{n}(i)=\left(R_{1}^{n}(i), R_{2}^{n}(i), \ldots, R_{m}^{n}(i)\right)$ in period $\mathrm{n}$ if the state of the market is $i$. As suggested by Çanakoğlu and Özekici (2010), it is assumed that the random returns in consecutive periods are conditionally independent given the market states. In other words, $R^{n}(i)$ is independent of $R^{k}(j)$ for all periods $k \neq n$ and states $i$ and $j$. Moreover, $R^{n}(i)$ and $R^{k}(i)$ are independently and identically distributed random vectors whenever $k \neq n$ This implies that the distributions of the asset returns depend only on the state of the market independent of time. For this reason, let $R(i)=R^{n}(i)$ denote the random return vector in any period $n$ to simplify the notations here.
Let $r_{k}(i)=E\left[R_{k}(i)\right]$ denote the mean return of the $k^{\text {th }}$ asset in state $i$ and $\sigma_{k j}(i)=\operatorname{Cov}\left(R_{k}(i), R_{j}(i)\right)$ denote the covariance between $k^{\text {th }}$ and $j^{\text {th }}$ asset returns in state $i$. The excess return of the $k^{\text {th }}$ asset in state $i$ is $R_{k}^{e}(i)=R_{k}(i)-$ $r_{f}(i)$. It follows that,

$$
\begin{gathered}
r_{k}^{e}(i)=E\left[R_{k}^{e}(i)\right]=r_{k}(i)-r_{f}(i) \\
\sigma_{k j}(i)=\operatorname{Cov}\left(R_{k}^{e}(i), R_{j}^{e}(i)\right)
\end{gathered}
$$

The notation here is such that $r_{f}(i)$ is a scalar and $r(i)=$ $\left(r_{i}(i), r_{2}(i), \ldots, r_{m}(i)\right)$ and $r^{e}(i)=\left(r_{1}^{e}(i), r_{2}^{e}(i), \ldots, r_{m}^{e}(i)\right)$ are column vectors for all $i$.

Let $X_{n}$ denote the amount of investor's wealth at period $\mathrm{n}$ and let the vector $u=\left(u_{1}, u_{2}, \ldots, u_{m}\right)$ denote the amounts invested in risky assets $(1,2, \ldots, m)$ respectively. Given any investment policy, the stochastic evolution of the investor's wealth follows the so-called wealth dynamics equation,

$$
\begin{aligned}
X_{n+1}(u) & =R\left(Y_{n}\right)^{\prime} u+\left(X_{n}-1^{\prime} u\right) r_{f}\left(Y_{n}\right) \\
& =r_{f}\left(Y_{n}\right) X_{n}+R^{e}\left(Y_{n}\right)^{\prime} u
\end{aligned}
$$

where $1^{\prime}=(1,1, \ldots, 1)$ is the column vector consisting of ' $\mathrm{m}$ ' ones. In a multi-period set-up, the wealth is reinvested recursively in each period using this equation.

The model assumptions can be summarised as

- There is unlimited borrowing and lending of the riskless asset in any period at a fixed rate,

- Short selling is allowed for all assets in all periods

- No capital withdrawals or additions are allowed, and

- $\quad$ Transaction fees and costs are negligible.

\section{THE PORTFOLIO PROBLEM MODEL}

The usual problem of portfolio optimization based on utility function can be written as,

\section{Problem 1:}

$\max E\left[U^{\prime}(u)\right]$

s.t. $u^{\prime} 1 \leq w$

$u \in X$,

where $U^{\prime}($.$) is the utility function of the investor, u$ is the vector of amounts to be invested in each asset, 1 is vector of ones with length $\mathrm{n}, \mathrm{n}$ is the number of assets in the portfolio, $X$ is the feasible region of investment i.e., $X=\{x ;-\infty<X<\infty\}$ and $w$ is the amount of wealth available for investment.

Why should one go for a pure integer solution in portfolio optimization?

One may wonder as to why it is so important to go for pure integer solution in the portfolio optimization problem? There are several real life issues which one may encounter while trying to apply any (non pure integer) solution to the portfolio problem. Some of them are:

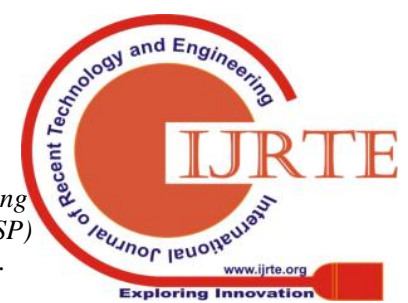


1. Stocks in the equity market are not available in fractions: Only in mutual funds can the agent think of buying stocks in fractions on behalf of the investors. This is because of the large number of investors involved. Elsewhere while buying any asset an individual investor is required to buy it in integer units only. Thus applying a non-integer solution may lead to misallocation of funds or may reduce the utility because of not investing the maximum amount of wealth available from the investor.

2. Expected Utility is quite sensitive to variations in the integer solutions: A small change in the integer solution yields a large difference in the expected utility value. Hence mere approximation of the non-integer solution will not give the optimum solution to the problem. For eg., consider a power utility function $U(x)=x^{2}$. Suppose there are two assets, A1 and A2 with price Rs. 10 and Rs 5 respectively and based on the above utility the optimal amount to be invested in these asset comes up to be Rs. 19 and Rs 6. i.e., the optimal utility value is supposed to be $(19+6)^{2}=625$. But 19/10=1.9 1 and 6/5=1.2 1 (after approximating to an integer). i.e., the investor can buy only one unit of each of the assets, which implies that only Rs. $(1 * 10+1 * 5=) 15$ has to be invested. Therefore ultimately the utility obtained is $(15)^{2}=225$. But a better solution to this problem would be to purchase 1 unit of $\mathrm{A} 1$ and 3 units of A2 .i.e., to invest Rs. $(1 * 10+3 * 5)=$ Rs. 25 which would give us the same optimal utility value. The variations can be quite high while dealing with two or more assets.

3. Approximated solution may be infeasible: It may so happen that after approximating the non-integer solution to an integer one, the feasibility of the solution may be lost, hence resulting in an impracticable solution. Even if one tries to round down the non-integer solutions to integer, then it may result in loss of a large amount of utility for the investor.

The integer portfolio problem based on a utility function can be written as,

\section{Problem 2:}

$\max E[U(d)]$

s.t. $d^{\prime} p \leq w$

$d \in X \cap I^{n}$,

where $U($.$) is the utility fintion of the investor, d$ is the vector of integers indicating the number of units of each asset to be purchased for the portfolio, $p$ is the corresponding vector of current prices of the assets in the portfolio and $I^{n}$ is the set of integer points in $R^{n}$.

Note that the above two models do not have any short selling restriction. However this can be modified by defining $\mathrm{X}$ as a bounded closed box specifying the limits of short sell.

Definition 1: For any $m \in I^{n}$, a set of integer points $\mathrm{N}_{\mathrm{B}}$ called its neighbourhood is defined as $N_{B} \supseteq\left\{m, m \pm 1_{i} ; i=\right.$ $1, \ldots, n$, where $1 i$ is an $n$ dimensional vector with 1 at the $i^{\text {th }}$ component and 0 at all other components.

Definition 2: For some $m \in X \cap I^{n}$, if the optimum solution is obtained within the neighbourhood of $m$ based on the objective function, the solution obtained is called the local optimum solution.

\section{INTEGER SOLUTION TO EXPECTED UTILITY MAXIMIZATION (ISEUM) PROBLEM ALGORITHM:}

Here an algorithm is presented for Problem 2. It is called an integer solution to Expected Utility Maximization (ISEUM) Problem Algorithm here. A random point $d$ in $X \cap I^{n}$ is taken and the integer local optimizer of Problem 2 based on $d$ is obtained and it is called as $d^{*}$.A new random point $d^{\prime}$ is selected. The integer local optimizer of Problem 2 based on $d^{\prime}$ is obtained as $d_{1}^{*}$. The values of the objective function at $d^{*}$ and $d_{1}^{*}$ are compared and the best one is taken to be $d^{*}$. This process is repeated a large number of times so as to converge at the approximate global optimum solution to the problem.

Lemma 1: Only that point in the neighbourhood of $d$ which generates an amount (based on current prices of assets) greater than the amount generated by $d$ can lead to improving the objective function.

Proof: The objective function depends on the utility function $U($.$) of the investor. From the property of utility function it is$ known that utility functions are non decreasing real valued functions. Also the utility functions depend on the amount invested. Thus given a set of integer points, one need not check the optimality of the objective function at each point in the set. Instead only that point can be considered whose corresponding amount is the largest.

Theorem 1: The search for the neighbourhood of a point can be shortened down to a single point which has the maximum corresponding amount associated with it.

Proof: Follows from the Lemma 1. In case of ties any one solution can be chosen.

Theorem 1 suggests that one need not check all the points in the neighbourhood while finding the local optimum solution. Thus by shortening the neighbourhood set, one can save a lot of time in the optimization process.

The steps of the algorithm are as follows:

Step 1: Let $N=N_{m}$ (a sufficiently large number) and initialize $j=1$. Obtain a random point $d$ in $X \cap I^{n}$. Get the neighbourhood of this point as $\mathrm{N}_{\mathrm{B}}$. Find the point in $\mathrm{N}_{\mathrm{B}}$ where the utility is maximum and call it as $d_{1}^{*}$.

Step 2: If $j>N_{m}$ terminate the algorithm else go to Step 3.

Step 3: If $d \neq d_{1}^{*}$, assign $d=d_{1}^{*}$. Find the local optimum solution in the neighbourhood of $d_{1}^{*}$ and call it as $d_{1}^{*}$. Repeat this step until $d$ becomes same as $d_{1}^{*}$.

Step 4: Obtain a new random point $d$ in $X \cap I^{n}$. Obtain the local optimum solution in its neighbourhood and call it as $d^{\prime}$. Let the optimum value of the expected utility at $d^{\prime}$ be $u_{1}^{*}$. Update $j=j+1$.

Step 5: If $u_{1}^{*}>U\left(d_{1}^{*}\right)$ then assign $d_{1}^{*}=d^{\prime}$ and then go to Step 2.

$$
\text { If } u_{1}^{*} \leq U\left(d_{1}^{*}\right) \text { go to Step } 4 .
$$

Repeat the above procedure for each market state.

Note that in Step 1, 3 and 4, the neighbourhood is shortened down to a single point by finding the corresponding amounts (by multiplying the vector of current prices of the assets with the vector of number of units of each asset to be purchased) and choosing the point that has the maximum amount.

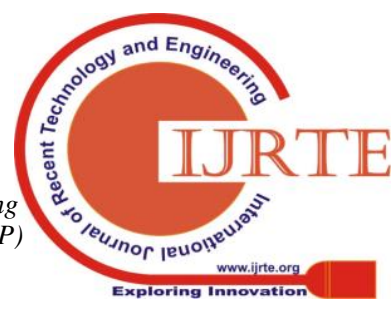


Now the convergence property of the ISEUM algorithm will be proved.

Let $S^{*}$ be the set of discrete global maximizers of Problem 2 and let $\mu\left(S^{*}\right)$ and $\mu\left(X \cap I^{n}\right)$ be the number of integer points in $S^{*}$ and $X \cap I^{n}$ respectively. Without loss of generality, suppose that $S^{*} \neq X \cap I^{n}$. Thus it is obvious that $\mu\left(S^{*}\right)>0$, $\mu\left(X \cap I^{n}\right)>0$ and $\mu\left(S^{*}\right)<\mu\left(X \cap I^{n}\right)$.

Let $d_{i}$ bet the random point drawn uniformly in $X \cap I^{n}$ in step 4 at the $i^{\text {th }}$ iteration. Maximizing the expected utility (amount) from $d_{i}$ will lead to $d_{i}^{*}$. Let $j>i$ be that iteration after $i$ that improves the expected utility value found at the $i^{\text {th }}$ iteration. Let $d_{j}$ bet the random point drawn uniformly in $X \cap I^{n}$ in Step 4 at the $j^{\text {th }}$ iteration. Maximizing the expected utility (amount) from $d_{j}$ will lead to $d_{j}^{*}$. Definitely, $E\left[U\left(d_{i}^{*}\right)\right] \leq E\left[U\left(d_{j}^{*}\right)\right]$ (because of Step 5). Similarly consider an another iteration say $k>j$, where the solution is better than the one obtained in the $j^{\text {th }}$ iteration. Therefore, a sequence $E\left[U\left(d_{i}^{*}\right)\right] \leq E\left[U\left(d_{j}^{*}\right)\right] \leq E\left[U\left(d_{k}^{*}\right)\right] \leq \ldots \leq$ $E\left[U\left(d^{*}\right)\right]$ is obtained, where $d^{*} \in S^{*}$ and $i<j<k<\cdots$. If no such $j, k, .$. (i.e., improvements to the solution) are available then for sufficiently large $N_{m}$ it can be safely said that $d_{i}^{*}$ itself will be $d^{*}$, the approximate global optimum solution to the Problem 2.

The solution obtained by this procedure may not give the same global optimum as the one obtained from the non-integer solution. In fact [25] proved that finding a feasible integer solution itself is NP-hard. Therefore an approximate global solution to the problem is obtained and it is seen by illustrations that these solutions are much better that the mere approximations of non-integer solutions.

Lemma 2: The probability that $d_{i} \notin S^{*}$ satisfies that $0<P\left\{d_{i} \notin S^{*}\right\}=1-\frac{\mu\left(S^{*}\right)}{\mu\left(X \cap I^{n}\right)}<$

1

And

$P\left\{d_{i} \notin S^{*}\right\}=P\left\{d_{j} \notin S^{*}\right\}$, for all $i<j$ and $i, j=1,2, \ldots$

Proof: Since $\mu\left(S^{*}\right)>0$ and $n_{i}$ is a random point drawn uniformly and independently in $X \cap I^{n}$. It is obvious that (1) and (2) hold.

Lemma 3: Let $q=P\left\{d_{i} \notin S^{*}\right\}$. for any $\delta>0$, then the following relation is satisfied,

$$
P\left\{E\left[U\left(d^{*}\right)\right]-E\left[U\left(d_{i}^{*}\right)\right] \geq \delta\right\} \leq q^{i-1} ; i=2,3, \ldots
$$

Proof: Refer Appendix.

Theorem 2: $d_{i}$ converges to a point in $S^{*}$ with probability 1 i.e.,

$$
P\left\{\lim _{i \rightarrow \infty} E\left[U\left(d^{*}\right)\right]-E\left[U\left(d_{i}^{*}\right)\right]=0\right\}=1
$$

Proof: Refer appendix.

\section{ILLUSTRATIONS}

Here we numerically illustrate the application of the results for the exponential, power and log utility functions. Suppose that the market has four risky assets and one risk-free asset. We assume the returns of the risky securities follow an arbitrary multivariate distribution. The data is obtained for the period September 2004 to September 2014 from daily price of four assets ( Tata chemicals, Bata India, Reliance communications and Syndicate Bank) traded in National stock exchange(NSE) of India; and the risk free asset return is obtained from the daily respective treasury rate of Reserve Bank of India. The states of the market are obtained by observing whether the S\&P CNX Nifty index price moved up or down in the previous 2 days. Therefore, in order to model prices as a Markov chain, 4 states are decided and labelled as $1=$ (up, up), $2=$ (up, down), $3=$ (down, up), and $4=($ down, down) depending on the movement of prices on previous two days. Similarly states which are depended on the previous 3 , 4, 5 days etc can also be considered. Let the transition probability matrix be denoted as Q. Please refer to Arif and Pakkala (2014) for more information on the data modelled here. The latest prices of the 4 securities Tata chemicals, Bata India, Reliance communications is Rs. (334.1, 1210.75, 151.45, 159.55) respectively.

Using historical data the transition probability matrix Q of the Markov chain is obtained as,

$$
Q=\left[\begin{array}{cccc}
0.637 & 0.363 & 0 & 0 \\
0 & 0 & 0.382 & 0.618 \\
0.685 & 0.315 & 0 & 0 \\
0 & 0 & 0.369 & 0.631
\end{array}\right]
$$

Observe that in Q, although theoretically possible, there is no transition from state 4 to state 4 .

Table 1: The return from the risk-free asset and the expected return of each risky asset for each state

\begin{tabular}{|c|c|c|c|c|c|}
\hline $\mathrm{i}$ & $r_{f}$ & $\mu_{1}(i)$ & $\mu_{2}(i)$ & $\mu_{3}(i)$ & $\mu_{4}(i)$ \\
\hline 1 & 1.0002 & 1.006 & 1.005 & 1.016 & 1.015 \\
\hline 2 & 1.0002 & 1.001 & 1.004 & 1.005 & 1.004 \\
\hline 3 & 1.0002 & 0.999 & 0.997 & 0.999 & 0.997 \\
\hline 4 & 1.0002 & 0.995 & 0.996 & 0.961 & 0.987 \\
\hline
\end{tabular}

The variance covariance matrices for the four states are denoted by $\Sigma(i), i=1,2,3,4$ which are $4 \mathrm{x} 4$ matrices. We consider the investors who is having initial wealth $x=$ Rs.10,000 and wants to maximize the expected utility of the terminal wealth

The expected utility function is approximated to four terms of its Taylor series expansion based on [26]. They argue the use of the first four moments in the approximation. Taylor series expansion is

$$
U(W)=\sum_{j=0}^{+\infty} U^{(j)}(\bar{W}) \frac{(W-\bar{W})^{j}}{j !}
$$

where $U^{(j)}(\bar{W})$ is the $j^{\text {th }}$ derivative of the utility function at $\bar{W}$. Taking expectations the above equation can be written as,

$$
\begin{aligned}
& E[U(W)]=U(\bar{W})+\frac{1}{2 !} U^{2}(\bar{W}) \mu_{p}^{2}+\frac{1}{3 !} U^{3}(\bar{W}) \mu_{p}^{3}+ \\
& \frac{1}{4 !} U^{4}(\bar{W}) \mu_{p}^{4}+E\left[R_{4}(W, \bar{W})\right]
\end{aligned}
$$

Published By:

Blue Eyes Intelligence Engineering and Sciences Publication (BEIESP 
where $R_{4}(W, \bar{W})$ is the remainder for the first four moments and $\mu_{p}^{n}$ is the $\mathrm{n}^{\text {th }}$ moment of the portfolio defined as

$$
\mu_{p}^{2}=E\left[(W-\bar{W})^{n}\right]
$$

Using the definitions in Jondeau and Rockinger (2006) for any market state, the second moment can be expressed as

$$
\mu_{p}^{2}=\gamma^{\prime} M_{2} \gamma
$$

where $M_{2}=\boldsymbol{\Sigma}($.$) is the covariance matrix. Similarly$

$$
\mu_{p}^{3}=\gamma^{\prime} M_{3}(\gamma \otimes \gamma)
$$

where $\otimes$ is the Kronecker product, and $M_{3}$ is the $4 \times 16$ co-skewness matrix with elements

$$
\left.s_{i j k l}=E\left[\left(R_{i}-\mu_{i}\right)\left(R_{j}-\mu_{j}\right)\left(R_{k}-\mu_{k}\right)\right)\right]
$$

for $i, j, k=1,2,3,4$. Finally,

$$
\mu_{p}^{4}=\gamma^{\prime} M_{4}(\gamma \otimes \gamma \otimes \gamma)
$$

where $M_{4}$ is the 4 x 64 co-kurtosis matrix with elements

$$
k_{i j k l}=E\left[\left(R_{i}-\mu_{i}\right)\left(R_{j}-\mu_{j}\right)\left(R_{k}-\mu_{k}\right)\left(R_{l}-\mu_{l}\right)\right]
$$

for $i, j, k, l=1,2,3,4$

Consider 3 types of investors each with exponential, power and logarithmic utility functions. The following are the outputs in each of these cases.

Investor 1:

Consider that an investor is having Exponential utility function defined as $U(x)=1000-\frac{e^{-0.001 x}}{0.001}$. The following tables give the solutions obtained by the non-integer optimization and from ISEUM.

Table 2: Integer Solution based on proposed procedure:

\begin{tabular}{|c|c|c|c|c|c|c|c|c|}
\hline \multirow{2}{*}{$\begin{array}{l}\text { Asset } \\
\text { Name }\end{array}$} & \multicolumn{2}{|c|}{ STATE 1} & \multicolumn{2}{|c|}{ STATE 2} & \multicolumn{2}{|c|}{ STATE3 } & \multicolumn{2}{|c|}{ STATE 4} \\
\hline & $\begin{array}{c}\text { Amo } \\
\text { unt }\end{array}$ & $\begin{array}{l}\text { un } \\
\text { its }\end{array}$ & $\begin{array}{l}\text { Am } \\
\text { ount }\end{array}$ & $\begin{array}{l}\text { un } \\
\text { its }\end{array}$ & $\begin{array}{c}\text { Amo } \\
\text { unt }\end{array}$ & $\begin{array}{l}\text { un } \\
\text { its }\end{array}$ & $\begin{array}{l}\text { Am } \\
\text { ount }\end{array}$ & $\begin{array}{l}\text { un } \\
\text { its }\end{array}$ \\
\hline $\begin{array}{l}\text { Tata } \\
\text { chemica } \\
\text { ls }\end{array}$ & $\begin{array}{l}1311 \\
2.34\end{array}$ & 39 & $\begin{array}{l}-410 \\
5.99\end{array}$ & $\begin{array}{l}-1 \\
3\end{array}$ & $\begin{array}{l}-844 \\
6.27\end{array}$ & $\begin{array}{l}-2 \\
6\end{array}$ & $\begin{array}{l}-769 \\
8.49\end{array}$ & $\begin{array}{l}-2 \\
4\end{array}$ \\
\hline $\begin{array}{l}\text { Bata } \\
\text { India }\end{array}$ & $\begin{array}{l}5130 \\
.96\end{array}$ & 4 & $\begin{array}{l}184 \\
65.8 \\
7 \\
\end{array}$ & 15 & $\begin{array}{l}-126 \\
69.6 \\
7 \\
\end{array}$ & $\begin{array}{l}-1 \\
1\end{array}$ & $\begin{array}{l}-967 \\
2.51\end{array}$ & -8 \\
\hline $\begin{array}{l}\text { Relianc } \\
\text { e } \\
\text { commu } \\
\text { nication }\end{array}$ & $\begin{array}{l}8994 \\
.92\end{array}$ & 59 & $\begin{array}{l}436 \\
4.69\end{array}$ & 28 & $\begin{array}{l}3147 \\
.92\end{array}$ & 20 & $\begin{array}{l}291 \\
4.61\end{array}$ & 19 \\
\hline
\end{tabular}

\begin{tabular}{|c|c|c|c|c|}
\hline Asset Name & $\begin{array}{c}\text { STATE } \\
1\end{array}$ & $\begin{array}{c}\text { STATE } \\
2\end{array}$ & STATE3 & $\begin{array}{c}\text { STATE } \\
4\end{array}$ \\
\hline Tata chemicals & 15 & -21 & -12 & -26 \\
\hline Bata India & -27 & 17 & -3 & 14 \\
\hline $\begin{array}{c}\text { Reliance } \\
\text { communications }\end{array}$ & 111 & 61 & 23 & -34 \\
\hline Syndicate bank & 195 & 44 & 80 & -17 \\
\hline Risk free asset & -104 & -201 & 14 & 97 \\
\hline
\end{tabular}

Minus sign indicates short selling

Table 3: State-wise distribution of Rs. 10000 among 5 assets and the corresponding approximated number of units that can be purchased with this amount:

\begin{tabular}{|l|l|l|l|l|l|l|l|l|}
\hline s & & & & & & & & \\
\hline $\begin{array}{l}\text { Syndica } \\
\text { te bank }\end{array}$ & $\begin{array}{l}1258 \\
8.96\end{array}$ & 78 & 493 & 30 & -152 & -9 & -459 & -2 \\
& & & & & $\begin{array}{l}91.1 \\
3\end{array}$ & 6 & 7.22 & 9 \\
\hline $\begin{array}{l}\text { Risk } \\
\text { free }\end{array}$ & -298 & -3 & -136 & -1 & 4325 & 43 & 290 & 29 \\
asset & 9 & 03 & 62 & 39 & 9.14 & 8 & 53.6 & 4 \\
\end{tabular}

Minus sign indicates short selling

It is seen from Table 2 and Table 3 that for each state of the

\begin{tabular}{|c|c|c|c|c|}
\hline State & 1 & 2 & 3 & 4 \\
\hline $\begin{array}{ll}\text { Non } & \text { Integer } \\
\text { Solution } & \\
\end{array}$ & 999.965 & 999.957 & 999.957 & 999.9 \\
\hline $\begin{array}{l}\text { Approximated } \\
\text { Integer Solution }\end{array}$ & 999.849 & 999 & 995 & 999.93 \\
\hline ISEUM & 999.959 & 999.956 & 999.951 & 999.955 \\
\hline
\end{tabular}
market the integer solution obtained from ISEUM is different from the approximated number of units to be purchased based on the amounts to be invested, obtained from the usual expected utility maximization procedure.

Table 4: Expected utility values based various solutions

It can be clearly seen from Table 4 that for each market state the expected utility for the approximated integer solution is always less than the expected utility value based on the integer solution obtained from the ISEUM algorithm. Thus if one merely approximates the solution rather than actually finding an integer solution then it is seen that in each state there is loss in utility for the investor. Also it is seen that the expected utility value is always greater for the non-integer solution when compared to the ISEUM. But this larger utility is in fact a pseudo optimal utility as it is not achievable in practice (due non-availability of assets in fractions for individual investors).

Investor 2:

Consider that an investor is having Log utility function defined as $U(x)=\log (x)$. The following tables give the solutions obtained by the non-integer optimization and from ISEUM.

Table 5: Integer Solution based on proposed procedure:

\begin{tabular}{|c|c|c|c|c|}
\hline Asset Name & $\begin{array}{c}\text { STATE } \\
1\end{array}$ & $\begin{array}{c}\text { STATE } \\
2\end{array}$ & $\begin{array}{c}\text { STATE } \\
3\end{array}$ & $\begin{array}{c}\text { STATE } \\
4\end{array}$ \\
\hline Tata Chemicals & $\mathbf{4 6}$ & $\mathbf{- 5 6}$ & $\mathbf{- 4 9}$ & $\mathbf{- 2 3 7}$ \\
\hline Bata India & $\mathbf{- 4 2}$ & $\mathbf{4 2}$ & $\mathbf{1}$ & $\mathbf{9 4}$ \\
\hline $\begin{array}{c}\text { Reliance } \\
\text { Communications }\end{array}$ & $\mathbf{2 0 6}$ & $\mathbf{1 1 5}$ & $\mathbf{1 5 4}$ & $\mathbf{- 1 9 3}$ \\
\hline Syndicate Bank & $\mathbf{1 6 0}$ & $\mathbf{- 1 2 5}$ & $\mathbf{- 4}$ & -33 \\
\hline Risk free asset & $\mathbf{- 1 1 4}$ & $\mathbf{- 1 9 9}$ & $\mathbf{2 5}$ & $\mathbf{9 9}$ \\
\hline
\end{tabular}

Minus sign indicates short selling 


\section{Utility Based Portfolio Optimization through Integer Programming Under Stochastic Markets}

Table 6: State-wise distribution of Rs. 10000 among 5 assets and the corresponding approximated number of units that can be purchased with this amount:

\begin{tabular}{|c|c|c|c|c|c|c|c|c|}
\hline \multirow{2}{*}{$\begin{array}{l}\text { Asset } \\
\text { Name }\end{array}$} & \multicolumn{2}{|c|}{ STATE 1} & \multicolumn{2}{|c|}{ STATE 2} & \multicolumn{2}{|c|}{ STATE3 } & \multicolumn{2}{|c|}{ STATE 4} \\
\hline & $\begin{array}{c}\text { Amo } \\
\text { unt }\end{array}$ & $\begin{array}{c}\text { unit } \\
\mathrm{s}\end{array}$ & $\begin{array}{c}\text { Amo } \\
\text { unt }\end{array}$ & $\begin{array}{c}\text { unit } \\
\text { s }\end{array}$ & $\begin{array}{c}\text { Amo } \\
\text { unt }\end{array}$ & $\begin{array}{c}\text { uni } \\
\text { ts }\end{array}$ & $\begin{array}{c}\text { Amo } \\
\text { unt }\end{array}$ & $\begin{array}{c}\text { unit } \\
\text { s }\end{array}$ \\
\hline $\begin{array}{c}\text { Tata } \\
\text { chemicals }\end{array}$ & $\begin{array}{c}4000 \\
0\end{array}$ & 119 & $\begin{array}{c}3000 \\
0\end{array}$ & 89 & $\begin{array}{c}-100 \\
00\end{array}$ & -30 & $\begin{array}{c}-200 \\
00\end{array}$ & -60 \\
\hline Bata India & $\begin{array}{c}4000 \\
0\end{array}$ & 33 & $\begin{array}{c}3000 \\
0\end{array}$ & 24 & $\begin{array}{c}-100 \\
00\end{array}$ & -9 & $\begin{array}{c}-200 \\
00\end{array}$ & -17 \\
\hline $\begin{array}{c}\text { Reliance } \\
\text { communica } \\
\text { tions }\end{array}$ & $\begin{array}{c}4000 \\
0\end{array}$ & 264 & $\begin{array}{c}3000 \\
0\end{array}$ & 198 & $\begin{array}{c}-100 \\
00\end{array}$ & -67 & $\begin{array}{c}-200 \\
00\end{array}$ & $\begin{array}{c}-13 \\
3\end{array}$ \\
\hline $\begin{array}{l}\text { Syndicate } \\
\text { bank }\end{array}$ & $\begin{array}{c}4000 \\
0\end{array}$ & 250 & $\begin{array}{c}3000 \\
0\end{array}$ & $\begin{array}{l}1 \\
8 \\
8\end{array}$ & $\begin{array}{c}-100 \\
00\end{array}$ & -63 & $\begin{array}{c}-200 \\
00\end{array}$ & $\begin{array}{c}-12 \\
6\end{array}$ \\
\hline $\begin{array}{c}\text { Risk free } \\
\text { asset }\end{array}$ & $\begin{array}{c}-150 \\
000\end{array}$ & $\begin{array}{c}-15 \\
20\end{array}$ & $\begin{array}{c}-110 \\
00\end{array}$ & $\begin{array}{c}-11 \\
15\end{array}$ & $\begin{array}{c}5000 \\
0\end{array}$ & $\begin{array}{l}5 \\
0 \\
6\end{array}$ & $\begin{array}{c}9000 \\
0\end{array}$ & $\begin{array}{l}-9 \\
11\end{array}$ \\
\hline
\end{tabular}

Minus sign indicates short selling

Table 7: Expected utility values based various solutions

\begin{tabular}{|l|c|c|c|c|}
\hline State & 1 & 2 & 3 & 4 \\
\hline Non Integer Solution & 9.34226 & 9.23994 & 9.21864 & 9.27582 \\
\hline $\begin{array}{l}\text { Approximated Integer } \\
\text { Solution }\end{array}$ & 8.96196 & 9.19000 & 9.06578 & 9.18151 \\
\hline ISEUM & 9.27432 & 9.22743 & 9.21140 & 9.23674 \\
\hline
\end{tabular}

One can observe similar conclusions for Tables 5, 6 and 7 as deduced for Tables 2, 3 and 4 respectively.

\section{Investor 3:}

Consider an investor having the Power utility function defined as $U(x)=\frac{2}{3} x^{0.5}$. The following tables give the solutions obtained by the non-integer optimization and from ISEUM.

Table 8: Integer Solution based on proposed procedure:

\begin{tabular}{|c|c|c|c|c|}
\hline Asset Name & STATE 1 & STATE 2 & STATE 3 & STATE 4 \\
\hline $\begin{array}{c}\text { Tata } \\
\text { Chemicals }\end{array}$ & 46 & -170 & 197 & -46 \\
\hline Bata India & -42 & 52 & -64 & 74 \\
\hline \begin{tabular}{|c} 
Reliance \\
Communicatio \\
ns \\
\end{tabular} & 206 & 28 & 97 & -190 \\
\hline Syndicate Bank & 160 & 4 & 53 & -204 \\
\hline $\begin{array}{c}\text { Risk free } \\
\text { asset }\end{array}$ & -114 & -11 & -15 & -32 \\
\hline
\end{tabular}

Minus sign indicates short selling

Table 9: State-wise distribution of Rs. 10000 among 5 assets and the corresponding approximated number of units that can be purchased with this amount:

\begin{tabular}{|c|c|c|c|c|c|c|c|c|}
\hline \multirow{2}{*}{$\begin{array}{c}\text { Asset } \\
\text { Name }\end{array}$} & \multicolumn{2}{|c|}{ STATE 1 } & \multicolumn{2}{|c|}{ STATE 2 } & \multicolumn{2}{c|}{ STATE3 } & \multicolumn{2}{c|}{ STATE 4 } \\
\cline { 2 - 9 } & $\begin{array}{c}\text { Amo } \\
\text { unt }\end{array}$ & $\begin{array}{c}\text { uni } \\
\text { ts }\end{array}$ & $\begin{array}{c}\text { Amo } \\
\text { unt }\end{array}$ & $\begin{array}{c}\text { uni } \\
\text { ts }\end{array}$ & $\begin{array}{c}\text { Amou } \\
\text { nt }\end{array}$ & $\begin{array}{c}\text { unit } \\
\text { s }\end{array}$ & $\begin{array}{c}\text { Amou } \\
\text { nt }\end{array}$ & $\begin{array}{c}\text { uni } \\
\text { ts }\end{array}$ \\
\hline $\begin{array}{c}\text { Tata } \\
\text { chemical } \\
\text { s }\end{array}$ & $\begin{array}{c}3000 \\
0\end{array}$ & 89 & $\begin{array}{c}3000 \\
0\end{array}$ & 89 & $\begin{array}{c}59042 \\
5.69\end{array}$ & $\begin{array}{c}176 \\
7\end{array}$ & $\begin{array}{c}-1383 \\
1.74\end{array}$ & $\begin{array}{c}-4 \\
2\end{array}$ \\
\hline Bata India & $\begin{array}{c}3000 \\
0\end{array}$ & 24 & $\begin{array}{c}3000 \\
0\end{array}$ & 24 & $\begin{array}{c}-69927 \\
7.95\end{array}$ & $\begin{array}{c}-57 \\
8\end{array}$ & $\begin{array}{c}80635 \\
.95\end{array}$ & 66 \\
\hline
\end{tabular}

\begin{tabular}{|c|c|c|c|c|c|c|c|c|}
\hline $\begin{array}{c}\text { Reliance } \\
\text { communic } \\
\text { ations }\end{array}$ & $\begin{array}{c}3000 \\
0\end{array}$ & $\begin{array}{c}19 \\
8\end{array}$ & $\begin{array}{c}3000 \\
0\end{array}$ & $\begin{array}{c}19 \\
8\end{array}$ & $\begin{array}{c}13242 \\
2.28\end{array}$ & 874 & $\begin{array}{c}-2589 \\
7.95\end{array}$ & $\begin{array}{c}-1 \\
71\end{array}$ \\
\hline $\begin{array}{c}\text { Syndicate } \\
\text { bank }\end{array}$ & $\begin{array}{c}3000 \\
0\end{array}$ & $\begin{array}{c}18 \\
8\end{array}$ & $\begin{array}{c}3000 \\
0\end{array}$ & $\begin{array}{c}18 \\
8\end{array}$ & $\begin{array}{c}73761 . \\
81\end{array}$ & 462 & $\begin{array}{c}-2929 \\
3.38\end{array}$ & -1 \\
84 \\
\hline $\begin{array}{c}\text { Risk free } \\
\text { asset }\end{array}$ & -110 & -11 & -110 & -11 & $\begin{array}{c}-87331 \\
.82\end{array}$ & $\begin{array}{c}-8 \\
8\end{array}$ & $\begin{array}{c}-1612 . \\
88\end{array}$ & - \\
1 \\
\hline
\end{tabular}

Minus sign indicates short selling

Table 10: Expected utility value based on various

solutions:

\begin{tabular}{|c|c|c|c|c|}
\hline State & 1 & 2 & 3 & 4 \\
\hline $\begin{array}{c}\text { Non Integer } \\
\text { Solution }\end{array}$ & 70.42052 & 67.89294 & 69.2799 & 68.4056 \\
\hline $\begin{array}{c}\text { Approximated } \\
\text { Integer } \\
\text { Solution }\end{array}$ & 66.23014 & 63.53197 & 66.33903 & 64.86745 \\
\hline ISEUM & 68.99811 & 67.31688 & 66.75024 & 67.72035 \\
\hline
\end{tabular}

One can observe similar conclusions for Tables 8, 9 and 10 as deduced for Tables 2, 3 and 4 respectively.

\section{CONCLUSIONS:}

Optimization of a portfolio based on utility functions has been a long line of research in the past. The solutions discussed earlier are approximated to integers because of availability of stocks in integer units. Earlier work does not include solutions that are directly integer based. In this paper, a procedure called the ISEUM is suggested, where the investor can obtain a pure integer solution to the portfolio optimization problem. This is discussed under the assumption of stochastic markets, where the market states follow a Markov chain. Illustrations showing three different types of investors are presented and the corresponding optimal integer solution is obtained. It is seen that in each case, considerable amount of utility may have been lost if one merely approximates the non-integer solution, instead of using ISEUM.

For future work it is suggested that, better optimization procedure could be developed which may help in reducing the computation time. Also one can compare the solutions for different levels of investor wealth.

APPENDIX

Proof of lemma 2: $d_{i}^{*}$ is a random variable dependent on $d_{i} ; i=1,2,3, \ldots$. Let $E_{i}$ be the event that $d_{i-1}^{*} \notin S^{*}$ i.e., $E\left[U\left(d_{i-1}^{*}\right)\right]<E\left[U\left(d^{*}\right)\right], i=2,3, \ldots$. For any $\delta>0$, the event that $E\left[U\left(d^{*}\right)\right]-E\left[U\left(d_{i-1}^{*}\right)\right] \geq \delta$ implies event $E_{i}$. Hence

$E\left[U\left(d^{*}\right)\right]-E\left[U\left(d_{i-1}^{*}\right)\right] \geq \delta \subseteq E_{i} ; i=2,3, \ldots$

Let $F_{i}$ be the event that in the ISEUM algorithm, maximization of expected utility(amount) converges finally to a point $d^{\prime} \in S^{*}$. Then $E_{i+1}=E_{i} \cap \bar{F}_{l}, i=$

$1,2, \ldots$. Furthermore, by noting that $\left\{d_{i} \in S^{*}\right\} \subseteq F_{i}$ and

$\bar{F}_{l} \subseteq\left\{d_{i} \notin S^{*}\right\}$, it is known that,

$$
P\left\{E_{i+1}\right\}=P\left\{E_{i} \cap \bar{F}_{l}\right\} \leq P\left\{E_{i} \cap\left\{d_{i} \notin S^{*}\right\}\right\}
$$

Since $d_{i}$ is drawn randomly and independently of $E_{i}$ and by inequalities (1) and (2), inequality (4) leads to,

$$
P\left\{E_{i+1}\right\} \leq P\left\{E_{i} \cap\left\{d_{i} \notin S^{*}\right\}\right\}
$$

Published By:

Blue Eyes Intelligence Engineering and Sciences Publication (BEIESP) (C) Copyright: All rights reserved. 


$$
\leq \cdots
$$

$$
\leq P\left\{E_{1}\right\} \cap
$$

$\prod_{l=1}^{i} P\left\{d_{l} \notin S^{*}\right\}$

(Since $P\left\{E_{1}\right\}=1$ by definition.)

$$
=\prod_{l=1}^{i} q=q^{i}
$$

Hence by (3) it can be deduced that $P\left\{E\left[U\left(d^{*}\right)\right]-\right.$ $\left.E\left[U\left(d_{i}^{*}\right)\right] \geq \delta\right\} \leq P\left\{E_{i}\right\} \leq q^{i-1} ; i=2,3, \ldots$ and Lemma 2 holds.

\section{Proof of Theorem 2 :}

To prove the theorem, it can be equivalently proved that $P\left\{\bigcap_{i=1}^{\infty} \bigcup_{l=i}^{\infty}\left[E\left[U\left(d^{*}\right)\right]-E\left[U\left(d_{i}^{*}\right)\right] \geq \delta\right]\right\}=0$ for all $\delta>0$

By Lemma 2 and Lemma 3 it can been seen that,

$$
\begin{gathered}
P\left\{\bigcap_{i=1}^{\infty} \bigcup_{l=i}^{\infty}\left[E\left[U\left(d^{*}\right)\right]-E\left[U\left(d_{i}^{*}\right)\right] \geq \delta\right]\right\} \\
\leq \lim _{i \rightarrow \infty} P\left\{\bigcup_{l=i}^{\infty}\left[E\left[U\left(d^{*}\right)\right]-E\left[U\left(d_{i}^{*}\right)\right] \geq \delta\right]\right\} \\
\leq \lim _{i \rightarrow \infty} \sum_{l=i}^{\infty} P\left\{\left[E\left[U\left(d^{*}\right)\right]-E\left[U\left(d_{i}^{*}\right)\right] \geq \delta\right]\right\} \\
\leq \lim _{i \rightarrow \infty} \sum_{l=i}^{\infty} q^{l-1}=\lim _{i \rightarrow \infty} \frac{q^{i-1}}{1-q}=0
\end{gathered}
$$

Therefore, (5) holds and the theorem is proved.

\section{REFERENCES}

1. Markowitz, H. M. (1952). Portfolio selection, Journal of Finance, 7(1), 77-91.

2. Sharpe, W. F. (1963). A Simplified Model for Portfolio Analysis. Management Science, 9(2), 277-293.

3. Merton R.C. (1969). Lifetime portfolio selection under uncertainty: The continuous-time case. The Review of Economics and Statistics, 51, 247-57.

4. Mossin, J. (1968). Optimal multiperiod portfolio policies. Journal of Business, 41, 215-29.

5. Sharpe, W. F. (2007). Expected utility asset allocation. Financial Analysts Journal, 5, 18-30.

6. Steinbach, M. C. (2001). Markowitz revisited: mean-variance models in financial portfolio analysis. Society for Industrial and Applied Mathematics Review, 43, 31-85.

7. Çanakoğlu, E., and S. Özekici. (2010). Portfolio selection in stochastic markets with HARA utility functions. European Journal of Operational Research, 201(2), 520-36.

8. Çelikyurt, U., and S. Özekici. (2007). Multiperiod portfolio optimization models in stochastic markets using the mean-variance approach. European Journal of Operational Research, 179, 186-202.

9. Çanakoğlu, E., and S. Özekici. (2009). Portfolio selection in stochastic markets with exponential utility functions. Annals of Operations Research, 166(1), 281-97.

10. Faaland, B. (1974). An integer programming algorithm for portfolio selection. Management Science, 20(10), 1376-1384.

11. Jacob, N. L. (1974). A Limited-Diversification Portfolio Selection Model for the Small Investor. Journal of finance, 29(3), 847-856.

12. Cooper, M. W. and K. Farhangian (1982). An integer programming algorithm for portfolio selection with fixed charges. Naval Res. Logistics Quart, 29, 147-150.

13. Ehrgott, M, Kathrin K, and Christian S. (2004). An MCDM approach to portfolio optimization. European Journal of Operational Research, 155(3), 752-770.

14. Konno, H. (1990). Piecewise linear risk function and portfolio optimization. Journal of the Operational Research Society of Japan, 33(2), 139-156.

15. Ballestero, E. and Romero, C. (1996). Portfolio selection: A compromise programming solution. Journal of the Operational Research Society, 47, 1377-1386.

16. Ballestero, E. (1998). Approximating the optimum portfolio for an investor with particular preferences. Journal of the Operational Research Society, 49, 998-1000.

17. Arthur, L. and Ghandforoush, P. (1987). Subjectivity and portfolio optimization. In K. Lawrence, J. Guerard, and G. Reeves, editors, Advances in Mathematical Programming and Financial Planning, 171-186. JAI Press, Greenwich, CO.

18. Hallerbach, W. and Spronk, J. (1997). A multi-dimensional framework for portfolio management. In M. H. Karwan, J. Spronk, and J. Wallenius, editors, Essays in Decision Making. A Volume in Honour of Stanley Zionts, 275-293, Springer, Berlin.

19. Pardalos, P., Sandstrom, M., and Zopounidis, C. (1994). On the use of optimization models for portfolio selection: A review and some computational results. Computational Economics, 7, 227-244.

20. Yin, G., and X. Y. Zhou. (2004). Markowitz's mean-variance portfolio selection with regime switching: from discrete-time models to their continuous-time limits. IEEE Transactions on Automatic Control, 49(3), 349-60.

21. Zhang, Q. (2001). Stock trading: An optimal selling rule. SIAM Journal on Control and Optimization, 40, 64-87.

22. Nagai, H., and S. Peng. (2002). Risk-sensitive dynamic portfolio optimization with partial information on infinite time horizon. Annals of Applied Probability, 12, 173-95.

23. Hernández-Hernández, D., and Marcus S. I. (1999). Existence of risk sensitive optimal stationary policies for controlled Markov processes. Applied Mathematics and Optimization, 40, 273-85.

24. Bielecki, T.R., D. Hernández-Hernández, , and S. R. Pliska. (1999) Risk sensitive control of finite state Markov chains in discrete time with applications to portfolio management. Mathematical Methods of Operations Research, 50, 167-88.

25. Mansini, R. and Speranza, M. (1999). Heuristic algorithms for the portfolio selection problem with minimum transaction lots. European Journal of Operational Research, 114, 219-233.

26. Jondeau, E., and Rockinger M. (2005). Optimal portfolio allocation under higher moments. European Financial Management, 12, 29-55.

\section{AUTHORS PROFILE}

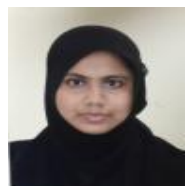

Dr. Afreen Arif $\mathbf{H}$, has done her doctorate from Mangalore University and is currently an assistant professor in Zayed university UAE. She has taught previously in St. Agnes college and Mangalore University as a lecturer. She is has got first rank in both in her bachelor's and master's degree program. She has got the gold medal for best outgoing student from St. Agnes college, Mangalore, Karnataka. She has been awarded the young statistician award for her research work from Indian society of probability and statistics in 2013. Her research interest is in portfolio optimization using stochastic models. She had been awarded the INSPIRE fellowship for her Ph.D. work from the Department of science and technology, Government of India. She has won Academic Excellency Award for outstanding performance in degree examination during the year 2008-2009 from Yenopoya Foundation, Mangalore, Principal's Roll of Honour, St. Agnes College, Mangalore in 2007 and 2008, All India Essay Writing Competition organized by the Ministry of Statistics and Programme Implementation, Central Statistical Office, Government of India. She also a chartered financial analyst from ICFAI, Tripura, India.

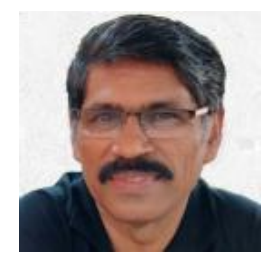

Dr T. P. M. Pakkala is a Professor of Statistics Nitte (Deemed) University. He is President of Association of British Scholars, Mangalore Chapter. He was acting Vice-Chancellor of Mangalore University for a brief period during 16-1-2016 to 21-1-2016. He was a member of Syndicate of Mangalore University. He was the Chairman of the Department of Statistics, Mangalore University during calendar years 2006, 2007, 2014 and 2015. He got his M. Sc. (Statistics) from University of Mysore with 2nd rank, and Ph. D. from Mangalore University. He also has a PG Diploma in Computer Applications.

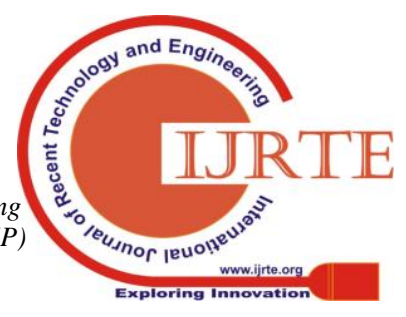


Utility Based Portfolio Optimization through Integer Programming Under Stochastic Markets

His teaching experience begins from Ahmednagar College Ahmednagar, Maharastra as a Lecturer in Statistics from September 1979 and served there until March 1982. Since March 1982 he has been serving at Mangalore University, as a Lecturer, a Reader ( from 1993) and a Professor (since 2001). He has been awarded a post-doctoral research award from University of New Brunswick, Canada for two years during 1996-1998. During this period he carried out research and teaching in this university. $\mathrm{He}$ is a recipient of prestigious Commonwealth Fellowship for post doctoral research and he carried out research at University of Exeter, England for one year during 2001 to 2002. Area of specialization: Inventory Modeling, Stochastic Modeling, Statistical Analysis of Finance, Rand EXECL programming, Research Methodology, and Data Envelopment Analysis. He has more than 40 research publications in reputed refereed international journals. He has around 75 seminar presentations and invited talks. 